\title{
Tekrarlayan Ameloblastoma: Olgu Sunumu
}

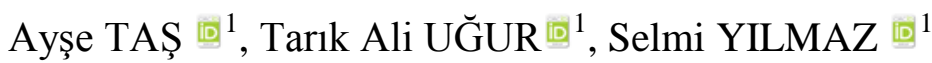

\begin{abstract}
ÖZ
Ameloblastoma, çene bölgesinde görülen bir benign tümördür. En sık 20-50 yaş aralığında izlenir. Mandibulayı maksilladan daha sık tutar ve \%80 oranında mandibular molar bölge ve ramus bölgesinde ortaya çıkar. Ameloblastoma yavaş büyür, ayrıca kemikte ekspansiyon ve destrüksiyon yapma eğilimindedir. Güncel sınıflamada ameloblastoma geleneksel, unikistik, ekstraosseöz/periferal ve metastaz yapan olmak üzere dört gruba ayrılmıştır. Ameloblastomalar kapsülsüz tümörlerdir ve bu sebeple çevre dokuya infiltre olurlar. Bu durum ise tümörün rekürrens riskini artırmaktadır. $\mathrm{Bu}$ nedenle büyük ameloblastoma olgularında mutlaka marjinal rezeksiyon yapılması gerekmektedir. Bu olguda 67 yaşında erkek hastanın, 33 yıl önce başka bir merkezde opere edilen ve şimdi tekrarlayarak büyük boyutlara ulaşmış olan mandibular ameloblastoma vakasının klinik ve radyolojik özelliklerinin sunulması amaçlanmıştır.
\end{abstract}

Anahtar Kelimeler: Ameloblastoma; mandibula; nüks.

\section{Recurrent Ameloblastoma: Case Report}

\begin{abstract}
Ameloblastoma is a benign tumor that occurs in the jaw area. It is most commonly seen in the 20-50 age range. It involves the mandible more often than the maxilla and occurs in $80 \%$ of the mandibular molar region and ramus region. Ameloblastoma grows slowly and also tends to expand and destroy bone. In the current classification, ameloblastoma is divided into four groups as traditional, unicystic, extraosseous / peripheral and metastasizing. Ameloblastomas are nonencapsulated tumors and therefore infiltrate the surrounding tissue. This situation increases the risk of tumor recurrence. Therefore, marginal resection must be performed in large ameloblastoma cases. In this case, it is aimed to present the clinical and radiological features of a 67-year-old male patient, who had been operated in another center 33 years ago and has now recurred to large dimensions.
\end{abstract}

Keywords: Amelobastoma; mandible; recurrence.

\section{GíRIŞ}

Ameloblastoma 1827'de Cusack tarafindan tanımlanmış, 1930'de Ivy ve Churchill tarafından isimlendirilmiştir (1). Dental folikül epitelini de içeren, odontojenik epitelin farklı kaynaklarından meydana gelen odontojenik bir tümördür. Çenelerde en sık görülen odontojenik tümör ameloblastomadır. Tüm çene tümörlerinin \%1'ini, odontojenik tümörlerin ise \%9-11'ini oluşturur $(2,3)$. \%80-85 oranında mandibulada ve \%80 oranında molar ve ramus bölgesinde görülse de mandibular simfiz bölgesine kadar yayılabilir $(4,5)$. En sık 20-50 yaş aralığında izlenir. Literatürde kadın ve erkeklerde görülme sıklığının eşit olduğu veya erkeklerde daha sık izlendiğine dair bilgiler mevcuttur. Ameloblastoma yavaş büyür, kemikte ekspansiyon ve destrüksiyon yapma eğilimindedir $(5,6)$. Bunun yanısıra kapsülsüz olduğu için çevre dokuya infiltre olur ve bu sebeple rekürrens oranı yüksek bir tümördür (7). Dünya Sağlık Örgütü (DSÖ)'nün 2005 yılında yayınlanan önceki sınıflamasında ameloblastoma; solid/multikistik, unikistik, periferal/ekstraosseöz ve desmoplastik olmak üzere dörde ayrılmıştır. 
Fakat bu sınıflama 2017 yılında güncellenmiş; çoğu ameloblastoma biyolojik farklılık olmaksızın kistik dejenerasyon gösterdiği için solid/multikistik teriminin kullanımından vazgeçilmiştir $(8,9)$. Bunun yanısıra desmoplatik ameloblastoma da ayırt edici histolojik görünümü olmasına rağmen ameloblastomanın diğer histolojik çeşitlerinden farklı davranışlar göstermediği için ana sınıflamadan çıkarılmıştır. Sonuç olarak güncel sinıflamada ameloblastoma geleneksel, unikistik, ekstraosseöz/periferal ve metastaz yapan olmak üzere dört gruba ayrılmıştır (10).

Ameloblastoma benign karakterlidir ve genellikle ağrısızdır. Fakat lokal agresif olabilmektedir ve dişlerde yer değiştirme, malokluzyon, çenelerde patolojik fraktür, fasiyal asimetri gibi önemli disfonksiyonlara yol açabilmektedir (11). Ameloblastoma radyografik olarak, ekspansif, sınırları sklerotik, multiloküler yapıya sahip litik bir lezyon görünümündedir (12). Bu multiloküler yap1 farklı boyutlarda geniş bölmelerden oluşuyorsa “sabun köpüğü” görüntüsü olarak adlandırılır (5).

Ameloblastomanın tedavisinde enükleasyon gibi konservatif cerrahi yöntemler kabul edilemeyecek kadar yüksek nüks oranına sahip olduğu için ideal cerrahi seçenek rezeksiyondur (13). Rezeksiyon, geniş bir kemik sınırı ile "en bloc" olarak tümörün çıkarılmasını içerir. Sonrasında kemik defekti doku greftleri ve/veya protez rehabilitasyonu ile rekonsrükte edilir. $\mathrm{Bu}$ radikal rezeksiyon işlemi hastalarda yüksek derecede morbiditeye neden olabilmektedir ve tedavi sonucunda lezyonun nüks etme riski ortadan kalkmaz (14).

$\mathrm{Bu}$ çalışmanın amacı 1987 yılında mandibula anteriorundaki ameloblastoma teşhisi konan tümör nedeniyle opere edilmiş hastanın 33 y1l sonraki nüks tablosunu klinik ve radyolojik özellikleriyle sunmak ve tartışmaktır.

\section{OLGU SUNUMU}

67 yaşında, sistemik olarak sağlıklı erkek hasta yüzünde şişlik şikayetiyle kliniğimize başvurmuştur. Hasta verdiği anamnezde, 1987 yılında ameloblastoma tanısıyla anterior mandibula bölgesinden operasyon geçirdiğini ve 1993 y1lına kadar rutin kontrollerine gittiğini belirtmiştir. Yapılan ekstraoral muayenede hastanın yüzünün sağ tarafında şişlik ve buna bağlı asimetri ile trismus izlenmiştir (Şekil 1).

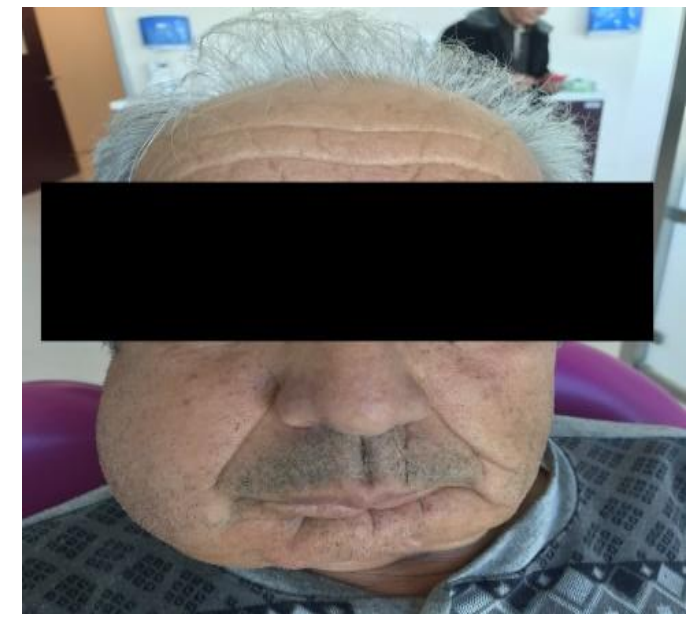

Şekil 1. Hastanın ekstraoral görüntüsü
Sağ submandibular lenfadenopati (LAP) mevcuttur. Yapılan intraoral muayenede sağ retromolar bölgede çevresi kırmızı-beyaz renkte, eritematöz yapıda bir intraoral fistül ağzı görülmüştür.

Radyolojik muayenede; rutin olarak alınan panoramik radyografide mandibulanın sağ tarafını kapsayan ve radyolusent bir görüntü veren 'sabun köpüğü', görünümüne rastlanmıştır (Şekil 2).

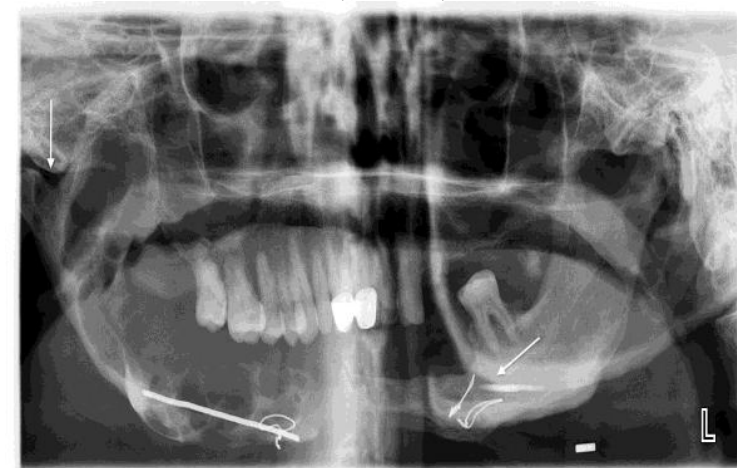

Şekil 2. Lezyonun panoramik film görüntüsü

Anterior mandibulada simfiz mandibulanın her iki tarafinda, korpusta alt kanin-premolar dişler hizasında tel osteotomi ile geçmiş lezyonun tedavi edildiği görülmüştür. Mandibular orta hatta fibula grefti vardır. Ameloblastoma nüksü şüphesi bulunan hastadan daha detaylı bir radyolojik değerlendirme yapabilmek amacıyla konik 1şınlı bilgisayarlı tomografi (KIBT) görüntüsü istenmiştir. KIBT değerlendirildiğinde mandibular kemikte, orta hattan başlayarak sağ mandibular korpusu, ramusu ve koronoid proçesi içine alan ve kısmen kondile uzanan; multiloküler, kemikte destrüksiyon ve ekspansiyon yapan radyolusent lezyon izlenmiştir (Şekil $3,4,5)$.

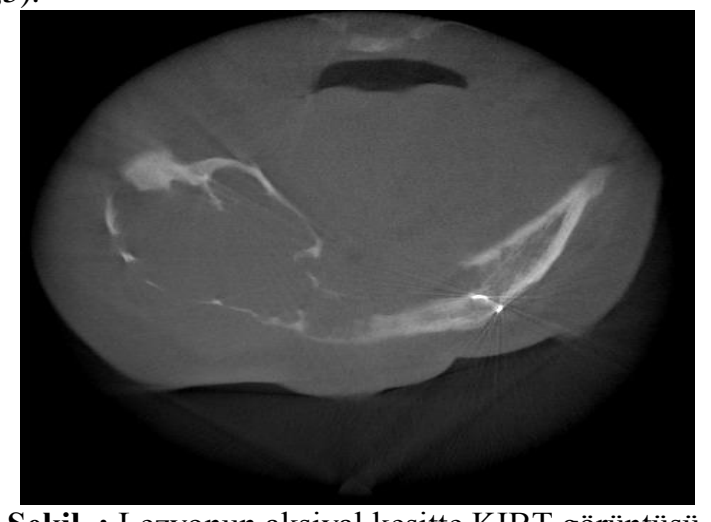

Şekil .: Lezyonun aksiyal kesitte KIBT görüntüsü

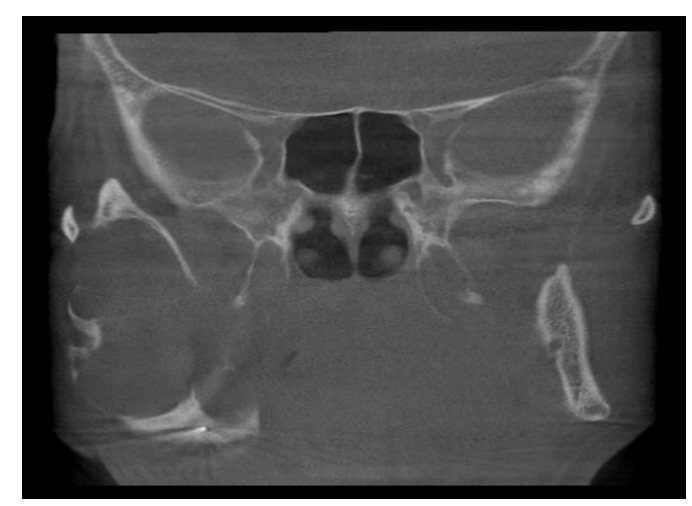

Şekil 4. Lezyonun koronal kesitte KIBT görüntü 


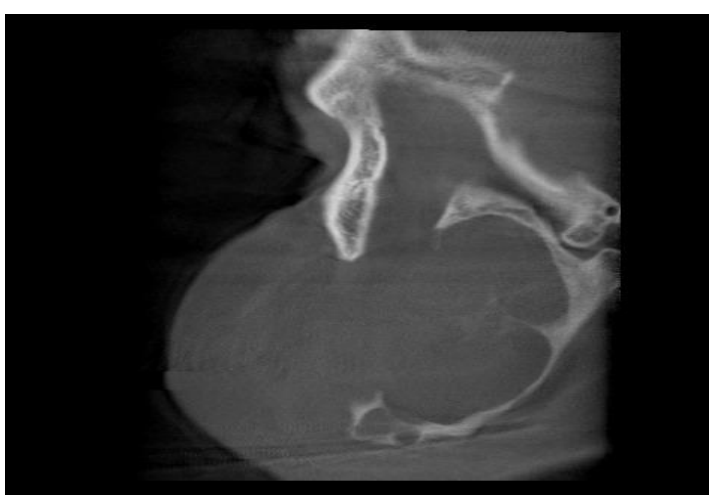

Şekil 5. Lezyonun sagittal kesitte KIBT görüntüsü

Yapılan klinik muayene, radyolojik muayene ve alınan anamnez sonucunda; 33 yıl önce mevcut olan ve tedavi edilen ameloblastomanın nüks ettiği belirlenmiştir. Tekrarlayan ameloblastoma teşhisiyle hasta, fakültemizin “'Ağız, Diş ve Çene Cerrahisi'” bölümüne yönlendirilmiş ancak tedaviyi kabul etmemiştir.

\section{TARTIŞMA}

Ameloblastoma \%80-85 oranında mandibulada ve $\% 80$ oranında molar ve ramus bölgesinde görülür $(4,5)$. Bizim olgumuzda literatürle uyumlu bir şekilde lezyon sağ mandibular kemiktedir. Genellikle 20-50 yaş aralığında görülür ve belirgin cinsiyet ayrımı yoktur (5). Olgumuzda hasta 67 yaşındadır, tümörü nüks etmiştir ve ilk ortaya çıktığı zaman göz önüne alındığında 34 yaş ile genel görülme yaşı özellikleriyle uyumludur.

Ameloblastoma, ekspansiyonla ve tam çıkarılmadığ 1 takdirde lokal nüks eğilimi ile karakterize, benign, intraosseöz, hızlı büyüyen epitelyal odontojenik bir tümördür (15). Kapsülsüz olması sebebiyle çevre dokuya kolayca infiltre olması nüks etme olasılığının yüksek olmasının sebebidir (7). Konservatif tedavi (marsupyalizasyon, enükleasyon, küretaj) kemiklerin bütünlüğünü korur ve mandibular kemikteki büyümeyi engellemez ancak \%55 ile \%90 arasında değişen yüksek bir nüks oranıyla ilişkilidir $(16,17)$. Diğer yandan radikal tedavi ise kozmetik ve fonksiyonel sekeller birakabilir ve serbest flep rekonstrüksiyonu gerektirebilir $(18,19)$. Olgumuzda ameloblastomanın ilk lokalizasyonu anterior mandibuladir. Fibula grefti ve tel osteotomi ile tedavi edilmiştir. Hastadan alınan anamneze göre ilk altı senelik takipte nüks öyküsü yoktur. Ancak uzun dönemde lezyonun tekrarladığ görülmektedir.

$\mathrm{Au}$ ve arkadaşlarının (20) ameloblastoma hastalarının uzun dönem değerlendirmesini yaptığ 37 yıllık retrospektif çalışmalarında da 5, 10 ve 15 yıllık nüks oranları sirasiyla $\% 9,3, \% 17,6$ ve $\% 24,4$ olarak bulunmuştur. Yani zaman ilerledikçe tümörün nüks ihtimali artmaktadır. Ayrıca radikal rezeksiyonun ameloblastomada düşük nüks oranı

için en önemli faktör olduğunu ve hastaların mutlaka uzun dönem takip edilmesi gerektiğini belirtmişlerdir. Chai ve ark. (21) mandibular ameloblastoma teşhisi konmuş 27 hastada $2 \mathrm{~cm}$ cerrahi sınırlı (büyük tümör durumlarında hemimandibulektomi) radikal rezeksiyon yapılmış vakalarda ortalama 5,6 yıl boyunca hiç nüks raporlamamıştır. Bunun sonucunda mandibular ameloblastomaların $2 \mathrm{~cm}$ cerrahi sınırlı segmental mandibulektomi ile tedavi edilmesi gerektiğini belirtmişlerdir. Ayrıca Hong ve ark. (22) 305 hastada yaptığı uzun süreli nüks takibi çalışmasında, sağkalım açısından konservatif ve kemik sınırlı rezeksiyon ile konservatif ve maksillektomi arasında istatistiksel olarak önemli farklar bulmuşlardır.

Ameloblastomalar kemik rezorpsiyonu radyolojik olarak belirgin hale gelmeden önce lezyonun çevresindeki spongioz kemiğin trabekülünü infiltre etme eğilimindedir. $\mathrm{Bu}$ nedenle, gerçek tümör sınırı çoğu zaman, görünen klinik veya radyografik sınırın ötesine geçmektedir. Tümörü küretaj ile çıkarma girişimi, kemikte daha sonra nükslere yol açabilecek küçük tümör adalarının kalmasına sebep olabilmektedir (23).

Literatürde de belirtildiği gibi nüks görülmesinin en önemli sebebi lezyon eksizyonunun yeterli düzeyde olmamasıdır. Mevcut çalışmalar ameloblastoma vakalarında etkin tedavinin en az 1-2 cm kemik sınırl radikal rezeksiyon olduğunu desteklemektedir $(10,21,24$ 27).

Sonuç olarak ameloblastoma çenelerin en sık görülen odontojenik tümörleri arasındır. Ayırıcı tanısında benzer multiloküler radyolusent lezyonların bulunması tümörün klinik ve radyolojik karakteristiğinin iyi bilinmesininin önemini ortaya çıkarır. Ameloblastomanın nüks oranının yüksek olması; radikal cerrahi tedaviyi ve uzun dönem hasta takibini zorunlu kilar.

Hasta Onamı: Hastaya yazılı ve sözlü bilgilendirme yapılarak, hastadan radyografik görüntülerinin ve fotoğraflarının kullanımı için aydınlatılmış onam formu alınmıştır.

Çıkar Çatışması: Yazarların beyan edecek çıkar çatışması yoktur.

Finansal Destek: Yazarlar bu çalışma için finansal destek almadıklarını beyan etmişlerdir.

Yazarların Katkıları: Fikir /Kavram: A.T., TA.U.; Tasarım: A.T., TA.U., S.Y.; Denetleme: A.T., S.Y; Kaynaklar: A.T., TA.U., S.Y.; Veri Toplama: A.T., TA.U., S.Y.; Analiz ve Yorum: A.T., TA.U., S.Y.; Literatür Taraması: A.T., TA.U.; Yazıyı Yazan: A.T., TA.U.; Eleştirel İnceleme: A.T., S.Y.

\section{KAYNAKLAR}

1. Angadi P. Head and Neck: Odontogenic tumor: Ameloblastoma. 2011.

2. Belli E, Rendine G, Mazzone N. Ameloblastoma relapse after 50 years from resection treatment. J Craniofac Surg. 2009; 20(4): 1146-9.

3. Masthan KMK, Anitha N, Krupaa J, Manikkam S. Ameloblastoma. J Pharm Bioallied Sci. 2015; 7(5): 167.

4. Henderson JM, Sonnet JR, Schlesinger C, Ord RA. Pulmonary metastasis of ameloblastoma: case report and review of the literature. Oral Surg Oral Med Oral Pathol Oral Radiol Endod. 1999; 88(2): 170-6.

5. White S, Pharoah M. Oral Radiology: Principles and Interpretation. 7th Edition. 2014.

6. Ramesh RS, Manjunath S, Ustad TH, Pais S, Shivakumar K. Unicystic ameloblastoma of the mandible - an unusual case report and review of literature. Head Neck Oncol. 2010; 14(2): 1.

7. Sato K, Sudo S, Fukuya Y, Sakuma H. Maxillary ameloblastoma with intracranial invasion--case 
report. Neurol Med Chir (Tokyo). 1994; 34(10): 7047.

8. Soluk-Tekkesin M, Wright JM. The world health organization classification of odontogenic lesions: a summary of the changes of the 2017 (4th) edition. Turk Patoloji Derg, 2018; 34(1): 1-18.

9. Wright JM, Vered M. Update from the 4th Edition of the World Health Organization Classification of Head and Neck Tumours: Odontogenic and Maxillofacial Bone Tumors. Head Neck Pathol. 2017; 11(1): 68-77.

10. Shi HA, Ng CWB, Kwa CT, Sim QXC. Ameloblastoma: A succinct review of the classification, genetic understanding and novel molecular targeted therapies. The Surgeon 2020.

11. Gerzenshtein J, Zhang F, Caplan J, Anand V, Lineaweaver W. Immediate mandibular reconstruction with microsurgical fibula flap transfer following wide resection for ameloblastoma. J Craniofac Surg. 2006; 17(1): 178-82.

12. Çöloğlu A. Oral Patoloji "Ağız Patolojisi." Yeditepe Üniversitesi Yayını; 2007.

13. Almeida R de AC, Andrade ES de S, Barbalho JC, Vajgel A, Vasconcelos BC do E. Recurrence rate following treatment for primary multicystic ameloblastoma: systematic review and metaanalysis. Int J Oral Maxillofac Surg. 2016; 45(3): 359-67.

14. McClary AC, West RB, McClary AC, Pollack JR, Fischbein NJ, Holsinger CF, Sunwoo J, Colevas AD, Sirjani D. Ameloblastoma: a clinical review and trends in management. Eur Arch Otorhinolaryngol. 2016; 273(7): 1649-61.

15. EI-Naggar AK, Chan JKC, Grandis JR, Takata T, Slootweg PJ. WHO Classification of Head and Neck Tumors. 4th ed. International Agency for Research on Cancer; 2017.

16. Takahashi K, Miyauchi K, Sato K. Treatment of ameloblastoma in children. $\mathrm{Br} \mathrm{J}$ Oral Maxillofac Surg. 1998; 36(6): 453-6.

17. Gardner DG. A pathologist's approach to the treatment of ameloblastoma. J Oral Maxillofac Surg. 1984; 42(3): 161-6.

18. Vayvada H, Mola F, Menderes A, Yilmaz M. Surgical Management of Ameloblastoma in the Mandible: Segmental Mandibulectomy and Immediate Reconstruction With Free Fibula or Deep Circumflex Iliac Artery Flap (Evaluation of the Long-Term Esthetic and Functional Results). J Oral Maxillofac Surg. 2006; 64(10): 1532-9.

19. Chaine A, Pitak-Arnnop P, Dhanuthai K, RuhinPoncet B, Bertrand J-Ch, Bertolus C. A treatment algorithm for managing giant mandibular ameloblastoma: 5-year experiences in a Paris university hospital. Eur J Surg Oncol EJSO. 2009; 35(9): 999-1005.

20. Au SW, Li KY, Choi WS, Su YX. Risk factors for recurrence of ameloblastoma: a long-term follow-up retrospective study. Int J Oral Maxillofac Surg. 2019; 48(10): 1300-6.

21. Chai KS, Omar FH, Mat Saad AZ, Wan Sulaiman WA, Halim AS. A 20-year experience of immediate mandibular reconstruction using free fibula osteocutaneous flaps following ameloblastoma resection: Radical resection, outcomes, and recurrence. Arch Plast Surg. 2019; 46(5): 426-32.

22. Hong J, Yun P-Y, Chung I-H, Myoung H, Suh J-D, Seo B-M, Lee J-H, Choung P-H. Long-term follow up on recurrence of 305 ameloblastoma cases. Int $\mathbf{J}$ Oral Maxillofac Surg. 2007; 36(4): 283-8.

23. Montoro JR de MC, Tavares MG, Melo DH, Franco $\mathrm{R}$ de L, Mello-Filho FV de, Xavier SP, Trivellato AE, Lucas AS. Mandibular ameloblastoma treated by bone resection and immediate reconstruction. Braz $\mathbf{J}$ Otorhinolaryngol. 2008; 74(1): 155-7.

24. Adeel M, Rajput MSA, Arain AA, Baloch M, Khan M. Ameloblastoma: Management and Outcome. Cureus. 2018; 10(10): e3437.

25. Pogrel MA, Montes DM. Is there a role for enucleation in the management of ameloblastoma? Int J Oral Maxillofac Surg. 2009; 38(8): 807-12.

26. Olaitan AA, Adeola DS, Adekeye EO. Ameloblastoma: clinical features and management of 315 cases from Kaduna, Nigeria. J Cranio-Maxillofac Surg Off Publ Eur Assoc Cranio-Maxillo-fac Surg. 1993; 21(8): 351-5.

27. Pandya NJ, Stuteville OH. Treatment of ameloblastoma. Plast Reconstr Surg. 1972; 50(3): 242-8. 